\title{
Nanominerals and potentially hazardous elements from coal cleaning rejects of abandoned mines: Environmental impact and risk assessment
}

Fdez Ortiz De Vallejuelo, Silvia; Gredilla, Ainara; Da Boit Martinello, Katia; Calesso Teixeira, Elba; Sampaio, Carlos Hoffmann; Madariaga, Juan Manuel; Silva Oliveira, Luis Felipe.

\begin{abstract}
Soils around coal mining are important reservoir of hazardous elements (HEs), nanominerals, and ultrafine compounds. This research reports and discusses the soil concentrations of $\mathrm{HEs}(\mathrm{As}, \mathrm{Cd}, \mathrm{Cr}, \mathrm{Cu}, \mathrm{Ni}, \mathrm{Pb}$, and $\mathrm{Zn}$ ) in coal residues of abandoned mines. To assess differences regarding environmental impact and risk assessment between coal abandoned mines from the Santa Catarina state, eighteen coal cleaning rejects with different mineralogical and chemical composition, from eight abandoned mines were collected. Nanominerals and ultra-fine minerals from mining-contaminated areas were analyzed by X-ray diffraction (XRD), field emission scanning electron microscopy (FE-SEM), and high-resolution transmission electron microscope (HR-TEM), providing new information on the mineralogy and nanomineralogy of these coal residues. The total contents of 57 elements (HEs, alkali metals, and rare earth elements) were analyzed by Inductively Coupled Plasma Mass Spectrometry (ICP-MS). The calculation of NWACs (Normalized Average Weighted Concentration), together with the chemometric analysis by Principal component analysis (PCA) confirmed the variability of the samples regarding their city and their mine of origin. Moreover, the results confirmed the existence of hotspots in mines near urban areas.
\end{abstract}

\section{Keywords}

Coal mining soil, Hazardous elements contamination, Hotspot identification, Normalized Average Weighted Concentration (NWACs), Principal component. 